\title{
Using Online Reviews in Social Care
}

\section{Lisa Trigg}

University of Kent

\section{University of Kent}

Cornwallis Building

Canterbury

Kent

CT2 7NF

Tel: 01227823963

pssru@kent.ac.uk

London School of Economics

London School of Economics

LSE Health \& Social Care

Houghton Street

London

WC2A 2AE

Tel: 02079556238

pssru@|se.ac.uk
Personal Social Services Research Unit

LSE Health and Social Care

PSSRU Discussion Paper 2836

July 2012

www.pssru.ac.uk 


\section{Abstract}

The emphasis placed on choice of social care provider means that there is an increasing need to furnish service users with reliable and up-to-date information on provider quality. In England, encouraging users and their carers to leave online feedback on providers is seen as one of the ways of improving the supply of information. However, using these channels for social care raises a number of issues, for example, the challenge of generating enough content to be of value, and the need to protect the anonymity of potentially vulnerable users. This paper aims to summarise these issues, by drawing upon the experiences of established review sites such as TripAdvisor and Amazon, as well as literature on decision-making and behaviour across social care and other sectors. The paper concludes that online reviews could assist in supporting both users and their carers to choose providers, however, they will need to be supported by carefully designed processes to maximise their usefulness. 


\section{Introduction}

Providing choice in social care has emerged as a central policy goal of a number of governments and England has been at the forefront of the shift towards self-directed care. Twenty nine per cent of eligible users of domiciliary care in England now use personal budgets (NHS Information Centre for Health and Social Care, 2012b), and the government has a goal of increasing this to 100 per cent of eligible service users by April 2013 (National Audit Office, 2011). In addition, a Law Commission report recommended that personal budgets are extended to allow the purchase of residential care (Law Commission, 2011). The provision of timely, reliable and accurate information on providers and quality is a critical component in supporting both users and their carers to make effective choices which meet both their needs and preferences. However, publishing information on quality in social care faces a number of challenges, from identifying meaningful and measurable indicators through to determining effective presentation formats and appropriate channels for communication. Information on social care services in England has typically been limited and difficult to access, despite numerous government-related projects to develop suitable communication channels (Baxter et al., 2008). A survey on personal budget users found that only just over half felt that their local authority had made it easy to obtain the relevant information to use personal budgets effectively, with large variations between councils (Hatton and Waters, 2011). A 2011 report on the care home sector in England by the Office of Fair Trading found that consumers are not always aware they have a choice and the information available can be complex and difficult to compare (Office of Fair Trading, 2011).

To tackle this problem, the government has announced that reviews of English social care services should be more widely available via the internet. In December 2011, the Care Services Minister announced that a new scheme would emulate the travel information site TripAdvisor:

It can't be right that you can find out exactly what a hotel or restaurant is like, in just a short time searching the web, but people have so much trouble working out the standards of different care homes and home care providers - when that choice is so much more important (BBC News, 2011).

The White Paper "Caring for our Future: Reforming Care and Support" published in July 2012 included an announcement that the Department of Health will work with organisations to develop comparison websites for social care (Department of Health, 2012). In addition, earlier in the year the Department of Health announced an award of $£ 160,000$ to Patient Opinion, a provider of health care reviews, to add social care to its portfolio (Todd, 2012). Patient Opinion, have already trialled this service, having received a grant to work with two care home providers in 2009 to test the idea of collecting and publishing user feedback (Munro and Ebbutt, 2011). It seems obvious that the internet, with its advantages for the collection and display of large amounts of information to a wide audience, should be leveraged more effectively. In theory, increasing the amount of information available over the internet should add breadth and depth to information seeking and decisionmaking.

For many, online review websites are now part of everyday life and figure in many different decision-making processes. Independent sites such as TripAdvisor and local restaurant review 
websites are used to plan holidays and eating out, book reviews are studied on Amazon and trips to the cinema are planned using sites such as the Internet Movie Database. Notwithstanding this, the use of this application for social care raises a number of questions. The purpose of this paper is to explore these issues, from the perspective of users and carers in their roles as both reviewers and information seekers, as well as from the perspective of providers and how they respond to reviews. The paper begins with an overview of online review sites and the information already available over the internet for care providers in England, before exploring the range of issues which affect the use of review sites in the social care sector. It then sets out policy recommendations which aim to deal with the limitations of this channel as a key source of information for social care users and their carers.

\section{Background}

The purpose of online reviews is to attempt to convert 'experience' goods into 'search' goods by reducing the costs and challenges of finding information on the attributes of a product or service (Klein, 1998). An experience good is one whose main characteristics cannot be known until after purchase and use, as opposed to search goods, for which full information can be obtained before purchase (Nelson, 1970, 1974). The nature of selling products and services over the internet means that virtually all products become experience goods (Weathers et al., 2007). Clothes cannot be tried on, televisions cannot be watched and flowers cannot be smelled. Retailers and independent websites have therefore created innovative ways to assist consumers with search activity. Online reviews are one method used by many websites, including independent websites such as TripAdvisor and retailers such as Amazon and eBay. This paper refers to research on three sites, TripAdvisor, Amazon and NHS Choices. These services are described in more detail in Box 1. 
Box 1: Rating Sites

\section{TripAdvisor}

TripAdvisor was established in 2000 and since then has become a byword for online consumer reviews and ratings. The site offers advice and reviews from travellers, along with links to providers and booking agencies. It receives more than 50 million unique monthly visitors and contains over 60 million reviews and opinions, and operates across 30 countries (TripAdvisor, 2012b). Its main source of revenue comes from fees for pay-per-click links and advertisements (Hulse, 2010). It is therefore incentivised heavily to invest in marketing its services, creating value-add services for both users and provider organisations, and ensuring that its products and processes are leading edge and fully functional. Users can vote on the helpfulness of reviewers and from this the site utilises algorithms to calculate a 'popularity indicator' to present an overall rating for each provider. Users can communicate with other users and reviewers both privately and in forums. Reviewers are rated on the volume of reviews and in addition certain reviewers are invited by TripAdvisor to be (volunteer) 'destination experts'. Hotels and restaurants can post responses to comments and, if they subscribe to the site, receive additional management information on traffic and activity (TripAdvisor, 2012a). Searching and buying travel and accommodation are the most popular informationseeking and purchasing activities on the internet, and therefore the fit of travel and accommodation reviews on the internet is a good one. In the UK in 2011, 86 per cent of internet users used the internet to assist with travel plans, and 78 per cent made travel reservations online (Dutton and Blank, 2011).

\section{Amazon}

Amazon was launched in 1995 as a book retailer, although in 2009, the sales of other products exceeded the sales of its 'core' products - books, movies and music - for the first time. Customer reviews have been an important part of Amazon since its launch, and much of the technology which drives review functionality has been patented and used by other businesses. Reviews serve three purposes for Amazon: to attract customer visits, to create a sense of community, and to increase the time spent on the site (Pinch and Kesler, 2011). All comments are moderated, only registered customers can post reviews and guidelines exist to avoid issues such as paid or plagiarised reviews (Amazon, 2012a). Reviews are rated by other users for helpfulness, and from this reviewers are ranked, with the Top 1000, 500, 100, 10 and No. 1 reviewer identified (Amazon, 2012b). These rankings are calculated by the use of a proprietary system with safeguards to prevent users working out how to 'game' the system (Pinch and Kesler, 2011). This is supplemented by Amazon's recommender systems, which use complex algorithms to present recommendations to registered customers, worked out by identifying similar customer profiles and buying patterns (Linden et al., 2003).

\section{NHS Choíces}

Online reviews were introduced onto the Department of Health's NHS Choices website for hospitals in 2007, and since then ratings have been introduced for GPs, dentists, pharmacies and opticians. The government has announced developments to this service to bring it more in line with the 'TripAdvisor' model (Neville, 2011). Feedback on the current site is governed by strict rules: comments have to be anonymised, moderators remove inappropriate comments, and as well as being published on the website, feedback and complaints are also forwarded to health care providers to enable them to take appropriate action (NHS Choices, 2012). NHS Choices reports that comments have been posted on more than $80 \%$ of GP practices, and many practices have received more than fifty comments. Overall, the site has received 85,000 comments on various services over the last three years (NHS Choices, 2011). A number of independent sites also allow patients to provide online ratings for health care providers in England, for example, www.iwantgreatcare.org.uk and www.patientopinion.org.uk. 
There are already a number of websites in England which are designed to provide information to assist users of social care services in identifying providers. The Social Care Institute for Excellence (SCIE) recently identified 35 separate independent sites (Steen, 2012). New sites continue to be developed, and SCIE itself is working on a new site www.findmegoodcare.co.uk, to be launched in late 2012 (Social Care Institute for Excellence, 2012). Many of these sites contain directories of residential and home care providers, and some provide links to the website of the social care regulator, the Care Quality Commission (CQC). A small number incorporate user reviews and recommendations, for example, www.carehome.co.uk. Some have a facility for providers to have enhanced listings, where they can post additional information regarding their services. Some websites publish their web traffic and have high numbers, with www.homecare.co.uk and www.carehome.co.uk claiming nearly 950,000 and over 10 million hits respectively in 2011 (carehomes.co.uk, 2012; homecare.co.uk, 2012). Interpreting these statistics is difficult given that the source of the traffic is not disclosed and might consist of provider organisations, local authority staff, provider staff, as well as users and carers. Previous research has found that these groups are bigger users of web-based information. For example, awareness and use of the now defunct CQC star ratings for providers was found to be significantly higher for local authority staff than it was for users and their carers. This research found that only $15 \%$ of users of either residential or home care were aware of the star ratings. Less than $1 \%$ of care home residents said the ratings were used to make the decision about the care home. Preferred sources of information were more likely to be word-of-mouth from friends or relatives, or information direct from care homes. Carers claimed to have higher awareness then users, though they were more likely to use feedback from relatives, current users, social services or the organisations themselves. For residential care, 45 per cent of carers were aware of the star ratings, although awareness for home care was lower, with around 20 per cent of carers aware of star ratings (Commission for Social Care Inspection, 2009). More recently an Office of Fair Trading (2011) report on residential care found that awareness of quality information on providers was very low.

There are other types of information services in England, such as FirstStopAdvice, which provides telephone and internet advice to older people looking for residential care and includes a directory of providers (Burgess, 2010). The purpose of Shop4Support, run by InControl, is to allow users to identify and purchase local care services directly (Harlock, 2009). Many English local authorities also have their own information websites, however these are generally found to have low levels of accessibility and readability when assessed against international Web Accessibility Initiative standards (Foley et al., 2005). 


\section{Challenges for Social Care Review Sites}

The increasing proliferation of websites in the social care sector suggests that this channel is ideally suited for channelling quality information to potential users. However, there are a number of issues which need to be addressed if provider review sites are to provide value for social care users.

\section{Social Care Users and Carers and the Internet}

The benefits of being connected to the internet are manifold. The internet offers the opportunity for making social contacts, as well as access to services, education and training, all of which are of benefit to many users of social care (Helsper, 2008). However, in the UK, 60\% of those aged 65 and over have never used the internet (Office for National Statistics, 2010). Some older people have extensive experience with using the internet, and many will have used or are still using computers in their work lives. However, both confidence and ability in using the internet can be affected as some older adults face deteriorating eyesight, short-term memory and/or motor skills (Redish and Chisnell, 2004). Disabled people are also disproportionately excluded from the internet. In 2010, $42 \%$ of disabled people lived in homes without internet access, compared with only $16 \%$ of nondisabled people (Department for Work and Pensions, 2012). The reasons for non-use by those with disabilities vary, but deterrents include the cost of purchasing, upgrading and training for assistive technologies such as screen readers and magnification. It is estimated that over eight million people have difficulties in using a standard PC and keyboard set-up (Foley et al., 2005). In addition, despite a legal obligation to support design for disabled people, four-fifths of websites fail to satisfy basic requirements (Disability Rights Commission, 2004).

Having access to the internet is also often conflated with an ability to make effective use of its multiple resources and applications. For older people, images of empowered silver surfers abound. However, there is a large gap between the applications generally used by older people, such as the email and information seeking activities, and content generation activities such as social networking and online reviews. The group least likely to generate content is the retired - only one-tenth of retired people who use the internet have posted photos, written a blog or used social networking sites (Dutton and Blank, 2011). This is not only due to a lack of IT literacy. In one study, older people who do not want to participate in social networking cite the lack of peer involvement, a suspicion of the type of people who do participate and a concern that involvement will lead to fraud or identify theft (Pfeil et al., 2009). Socio-economic factors and education have also been found to be important in determining whether users actively generate content (Hargittai and Walejko, 2008; Helsper, 2008; Blank and Reisdorf, 2012). This is relevant given that disabled people are more likely to be unemployed, less likely to hold qualifications and more likely to live in poor households (Department for Work and Pensions, 2012). This skew towards the educated and wealthy is backed up by findings from other sectors. US-based research in health care found that online reviewers are likely to be younger, healthier and more affluent than health care users overall (Lopez et al., 2012). A 2007 survey of over 2,000 TripAdvisor reviewers, albeit self-selected, found that nearly $70 \%$ were educated to under- or post-graduate level and $85 \%$ earned US\$50,000 or above. In addition, over $70 \%$ had taken three or more trips in the last year, with only $2.7 \%$ of respondents taking no trip at all (Gretzel et al., 2007). There are therefore likely to be some notable differences between the way in 
which online reviewers and social care users and their carers access and interact with the internet. These differences are not restricted to age or level of disability, but are also closely linked to socioeconomic factors.

\section{Social Care Users and Carers as Reviewers}

Assessing the quality of services of any type is problematic. Services are intangible and defined as much by the process of providing the service as they are by the final outcome. A service is a 'performance' by a human being, whether it is by a caregiver, a hotel receptionist or a waiter in a restaurant. The service can vary each time it is performed, even by the same individual, ensuring that services are heterogeneous and consistency is difficult to achieve. Finally, for many services, it is impossible to separate the production and consumption of services (Parasuraman et al., 1985). The quality of social care is significantly affected by the health and functional status of the user, as well as the interactions between them and their caregiver (Davies and Knapp, 1980). Collecting the views of users on the quality of the service will provide helpful insight, but will also be affected by the user's own impact on the service as co-producer, as well as being influenced by the user's own expectations of the service.

In health care, there has been a great deal of controversy over whether patients can be effective judges of medical care and therefore whether online reviews should be allowed (McCartney, 2009; Davie, 2011; Neville, 2011). In contrast, the bulk of social care is 'non-technical' and a user (or their carer) will be more than competent to decide whether a professional provided care with respect and sensitivity or fulfilled basic expectations such as arriving on time or turning up at all. However there can be a relatively long 'learning period' as users build up enough experience with a provider to provide an effective assessment (Grabowski and Town, 2011). In addition, focusing on the user's experience of the service process might leave an important information gap on whether the service is achieving the desired outcomes in terms of quality of life, as well as a potential lack of feedback on technical and clinical aspects of care. This latter issue has been observed in health care, where patients tend to focus on the non-technical aspects of care, for example, the interpersonal skills of clinicians and systems and organisational issues such as the courtesy of reception staff and availability of appointments (Chang et al., 2006; Lopez et al., 2012).

To provide accurate information for users, review websites aim to harness the 'wisdom of crowds' (Surowiecki, 2004). By collecting enough opinions, an average rating will emerge which reflects an accurate evaluation of the service. A high volume of reviews is essential and volume can be more important for users than the opinions contained in the reviews (Park et al., 2007). For reviews of hotels, the length of stay of guests means that even small establishments could accumulate multiple reviews. A well-established and popular 20 room hotel will host hundreds of short-stay guests over the course of a year. Even for a service like NHS Choices, with the number of patients per GP at over 1,500 , there is the possibility that over time, the 'wisdom of crowds' will emerge.

In contrast, for care homes, the turnover of residents would typically be too low to support a high volume of reviews. The average length of stay in a care home England is 1.6 years (Forder and Fernandez, 2011). With two-thirds of care home residents suffering from dementia (Knapp et al., 2007), the pool of people who both have the mental capacity and who are prepared to post reviews 
grows smaller. Home care agencies will have a similar problem in generating reviews. With low user turnover and small numbers of clients, the potential for multiple users to leave feedback on a single provider is relatively limited. With an average of 2.3 clients per user (Eborall et al., 2010), feedback on personal assistants would also be limited. In addition, to achieve a high volume of reviews, a contributing factor is the level of motivation which exists among potential reviewers. One commentator calculated that for a popular Harry Potter book on Amazon, only one in 1,300 purchasers wrote a review (Spool, 2009). Researchers reviewing reviews on 300 doctors in Boston found only 66 (mostly positive) reviews across 33 separate sites. This contrasted with 38 reviews on a single site for a single local restaurant (Lagu et al., 2010).

Using different consumer products, Sundaram and colleagues (1998) identified a number of different motivating factors for posting reviews, shown in Table 1. In health care, the risk of users seeking vengeance by expressing negative comments is cited as a reason not to allow feedback to be posted (Davie, 2011). However, both Sundaram's research, and a study of TripAdvisor reviewers by Gretzel and colleagues (2007) found limited evidence of this as a motivator. What both studies did find was that negative reviews were more often posted for altruistic reasons to prevent other users from going through a similar experience. Both these studies show that many of the drivers for posting reviews are due to intrinsic motivators such as altruism and self-enhancement, and it is therefore difficult to find ways to motivate customers to post reviews (Gretzel et al., 2007). Both TripAdvisor and Amazon attempt to address this by implementing awards for the value and quantity of reviews. While this is partly to indicate the credibility of the reviewer it also serves to recognise and reward the reviewer's contribution, which in turn is intended to motivate them to write further reviews. The authors of the TripAdvisor study suggest that the simplest way of motivating people to contribute is to remind them of the value they themselves gained from reading reviews, the potential contribution they could make, and simply by making it as straightforward as possible to contribute.

One option for in the social care sector is to encourage the carers and families of social care users to post reviews. However, motivating users and carers to post reviews will be affected by the importance of preserving anonymity - of both the users and the care professionals who support them. If a reviewer on TripAdvisor has a negative experience with a hotel, they can post a critical review with relative impunity. Unless the traveller has a need to return to the same location, he or she has an almost infinite number of holiday destinations to choose from. They are unlikely to face any ramifications from posting the review - apart from an online response from the hotel owner, or potentially the ire of travellers who disagree. In contrast, users of social care and their carers have a number of additional constraints which will impact on their propensity to post and use on-line reviews. The risks of exposing an already vulnerable and fragile user to the repercussions of negative feedback could be too great, and the likelihood of swapping to a different provider is also low. This is particularly true in the care home sector due to the average length of stay and the difficulties involved with moving to a new care home. 
Table 1: Motivation for Word-of-Mouth Communication regarding Products and Services

Motivation

Altruism

Product involvement

Self-enhancement

Helping the

organisation

Anxiety reduction

Vengeance

Advice seeking

\section{Description}

Reviewers want to guide others to make a positive 'purchasing decision' - or to avoid making a negative decision

The reviewer wants to express their excitement and enjoyment regarding a product with which they feel very involved

Reviewers post to boost their image as an expert and to seek approval from the online community

Reviewers want to promote the organisation to support it with retention or acquisition of consumers (effectively another form of altruism)

Reviewers are seeking a cathartic way of venting their anger, frustration or disappointment

Reviewers are attempting to retaliate against an organisation for a poor experience

Reviewers wish to take action against the organisation but are looking for advice from others on how to do so effectively

Source: Adapted from Sundaram et al 1998

There is also a need to preserve the anonymity of staff, or at least to ensure that comments are not libellous, threatening or abusive. The rules for feedback for NHS Choices state that reviewers cannot name staff, whether clinical or administrative (NHS Choices, 2012). Between late 2009 when the service was launched and 2011, nearly 2,000 comments were rejected by the moderators, out of nearly 24,000 comments on GP practices (Davie, 2011). In the social care environment, it will be essential to protect the workforce from unduly negative or unfair feedback in an environment where 'troll' reviewers are able to post inflammatory, discriminatory or derogatory comments which they would not be prepared to share in the offline world (Zhuo, 2010). However, this also limits the usefulness of feedback in social care where the ability to comment on the quality of one-to-one interactions with specific individuals is crucial.

Finally, the probability of a user or carer posting social care reviews is further reduced by the way in which social care users interact with the internet. Users and carers are unlikely to post reviews if they lack the experience, skills or interest in generating content and reviews on the web more generally. While it is unwise to make generalisations about different groups and their use of the internet, it is also important to consider both access and usage issues for both users and their carers when assessing the potential value of review websites.

\section{Information Seekers}

The main purpose of publishing feedback on the internet is to enable users and their carers to make informed decisions about providers. However, designing effective channels has to take into account 
a number of characteristics of the decision-making process in social care and the circumstances surrounding it, the strategies people adopt to make choices, and the difficulties of interpreting feedback without context.

The task of choosing a provider of social care can be stressful and difficult. For care homes, relatives and carers often take on the decision-making role, frequently because the move is unplanned and in response to a specific event such as a hospital stay or the death of a spouse (Davies and Nolan, 2003). The time pressures involved mean that the decision is likely to be constrained by issues such as the availability of a place (Netten et al., 2001) as well as funding issues or the eligibility of the person for the specific care home (Davies and Nolan, 2003). The opportunity to consider quality information is limited, and is therefore not usually considered by residents or their carers when first seeking a place (Commission for Social Care Inspection, 2009). In contrast, when asked, over 90 per cent of TripAdvisor respondents said they found planning 'fun', 'enjoyable' and 'something they like to do' (Gretzel et al., 2007).

The assumption behind publishing information about quality is that, armed with data and facts on performance, the consumer will make an informed, rational choice of provider (Fasolo et al., 2010). However, research in decision theory shows that the way people make decisions varies with a number of task-related factors, such as the time available to make the decision, the number of choices and the number of features to be considered. Preferences are constructed on the spot as people acquire information (Slovic, 1995), and as the amount of information and complexity of the decision task increases. In these situations, people adopt non-compensatory strategies, taking less systematic approaches to how they evaluate information (Payne et al., 1993). Studies in health care conclude that there is a need to be selective with information in order to reduce the burden on consumers and to support them to make better decisions (Finucane et al., 2002; Hibbard et al., 2002; Peters et al., 2007). In addition, age-related changes in cognitive ability and decision-making processes reinforce the need to plan the content and quantity of information with care (Finucane et al., 2002; Mata et al., 2007).

This is particularly true when it comes to the use of user feedback and testimonials. The impact of online reviews in making decisions is unclear. Even in consumer markets such as movie and video game reviews it has been difficult to establish causality between reviews and purchasing decisions (Duan et al., 2008; Zhu and Zhang, 2010). However, there is some evidence on the use of personal testimonials which should be considered when planning the publication of reviews to assist in making decisions about social care services. Testimonials have been shown to have a disproportionate impact on choices, despite the fact that a testimonial only represents the view of one person. When people were asked in an experiment whether they would opt for bypass surgery or balloon angioplasty to treat angina, patient testimonials were found to have a much greater effect on the decision than statistical information on recovery and effectiveness rates (Ubel et al., 2001; Fagerlin et al., 2005). Anecdotal information can be much clearer for information seekers - a testimonial will be unequivocal about the person's survival and it will reveal whether the patient improved, which is easier to relate to and potentially more compelling than knowing the rate of success of a surgical procedure. The difficulties experienced by many in understanding complex information also influence how likely consumers are to turn to testimonials (Fagerlin et al., 2005). In the United States, comprehensive information on nursing home quality is provided via the Nursing 
Home Compare website. However, the lack of user reviews is seen as an important reason why the site is not better used, supporting the view that consumers are as interested in seeing the subjective reviews of other users as they are in formal quality reporting (Lagu and Lindenauer, 2010). Of those who were aware of $\mathrm{CSCl}$ ratings on care homes in England, only approximately half agreed strongly that they had confidence that the regulator's ratings would provide a good measure of the quality of the home (Commission for Social Care Inspection, 2009), suggesting that there is a similar interest in England in the views of other users.

Word-of-mouth is recognised as the key source of information for people seeking a social care provider (Sykes et al., 2008; Commission for Social Care Inspection, 2009). Publishing feedback on the internet can be described as an online form of word-of-mouth communication. However, a fundamental difference between offline and online word-of-mouth communication is the lack of social cues. In a face-to-face situation, people use signals such as gender, age, ethnicity and socioeconomic background to determine the 'source credibility' of the person communicating their opinion (Brown et al., 2007). Commercial sites look for ways to manage this issue: TripAdvisor and Amazon both have systems where other users can rate the helpfulness of reviews, and this process is in turn used to identify and highlight helpful or credible reviewers. On services like TripAdvisor, readers also develop various strategies on whether to consider or dismiss reviews. Europeans have been known to dismiss reviews by Americans because they are too 'picky', with Americans avoiding European reviewers as they feel Europeans have low expectations (Keates, 2007). In using reviews on social care, the onus on information seekers is to interpret user feedback and somehow determine source credibility, while taking into account at least three complex issues: the user's impact on quality as a co-producer of care; the influence of the user's expectations on their perception of care; and the case mix of the provider. The presence of user information is 'significantly and positively associated' with the perceived helpfulness of reviews (Forman et al., 2008). The necessity for some reviewers to remain anonymous in the social care sector will therefore deprive readers of some of the key information they need to determine the credibility of the reviewer and applicability of the review.

To add to this complexity is the risk of social care providers posting their own reviews and, in doing so, in effect sabotaging information seekers. In the past, Amazon reviews have been posted by public relations companies on behalf of clients, negative reviews have been posted by competitors (Streitfield, 2011) and reviews have even been plagiarised (David and Pinch, 2005). Amazon now has guidelines for reviewers to attempt to prevent this type of behaviour (Amazon, 2012a). For hotel and restaurant owners, there is concern over the volume of malicious reviews on TripAdvisor, with complaints and accusations on issues ranging from food poisoning and bed bugs to theft and assault (Raphael, 2011). In addition, the posting of reviews on TripAdvisor by providers (either a positive review about their own establishment or a negative one about a competitor's) led the Advertising Standards Agency to judge that it can no longer promote 'trusted reviewer' status on its UK site (Advertising Standards Authority, 2012). One author has suggested that eventually all providers will have to post reviews to compensate for the belief by users that it is inevitable that there will be at least one positive self-posted review (Dellarocas, 2006). Any service which hosts online reviews for social care will need to have processes for managing these hazards. 
When evaluating the effectiveness of reviews for information seekers, the ultimate question has to be whether access to information changes the final decision. The 2009 Commission for Social Care Inspection showed that only $1 \%$ of care home residents in England made use of the star ratings system in choosing a care home, although it is not clear whether it determined the selection of care home. In the US, the introduction of formal quality reporting on Nursing Home Compare has had little impact on the occupancy rates of nursing homes (Stevenson, 2006). Drawing from health care, only $4 \%$ of those making choices about English hospitals consulted NHS Choices, and again the extent to which this influenced the patient's decision is unclear (Dixon et al., 2010). Interestingly, in a recent study of three hospitals with widely-publicised major adverse events (including Mid Staffs Hospital), patient flows were only affected for one of the hospitals, and this was only a temporary change (Laverty et al., 2012), suggesting that publicly available information has a limited effect on decision-making.

\section{Providers of Social Care}

The focus of this paper so far has been on how social care users might interact with online reviews for the selection of providers. The other use for publishing information is to incentivise quality improvement (Berwick et al., 2003). The theory is that, where consumers or official sources publish negative results or feedback, the provider will recognise the threat of losing customers, and adjust their behaviour accordingly. The bulk of the research in this area for social care is again from Nursing Home Compare and it shows mixed results. While about two-thirds of nursing homes in one US study said that they were using the information from Nursing Home Compare for quality improvement, there was little evidence of fundamental changes to areas such as leadership or resourcing (Mukamel et al., 2007). However, in health care, there is evidence of some responsiveness by hospitals to published quality information (Fung et al., 2008), with both positive and negative effects, including distorted clinical priorities and tunnel vision (Mannion et al., 2005).

For providers of social care, there are at least three potential barriers for this approach to quality improvement. The first is the supply issues which exist in many areas of social care in England. For residential care, providers can be chosen simply because they have a place available, and there is also a low likelihood of moving between care homes, even if quality is poor, with relocation linked to higher death rates (Laughlin et al., 2007). In theory, for domiciliary care, the option of exit would appear much easier given a lower level of logistical issues associated with changing providers. However, even in this sector there is a reluctance to switch, even where there is dissatisfaction with the service (Office for Public Management et al., 2010). Concerns have also been raised about the adequate supply of personal assistants available to be employed through personal budgets (Scourfield, 2005; Adams and Godwin, 2008). The second barrier is the financial constraints which face the sector. Government spending on social care has fallen by $4 \%$ in real terms since 2005-06, and by $29 \%$ since $2000-01$ (NHS Information Centre for Health and Social Care, 2012a). As a result, care home providers, for example, have less to spend on quality improvement initiatives including training, recruitment and retention or investment in new equipment (Royal College of Nursing, 2012). Finally, in order for this channel to be effective as a tool for quality improvement, it is necessary to have in place communications processes and protocols to ensure that providers are aware of feedback. In a market dominated by small providers, it is unlikely that providers will have the capacity or capability to proactively search for, access and take action on online reviews. The 
TripAdvisor service provides a sophisticated management dashboard for providers to use to leverage reviews for business improvement (TripAdvisor, 2012b). However, even in the highly competitive London hotel market, there is little evidence that businesses make use of TripAdvisor feedback, or take the opportunity to respond to negative comments (O'Connor, 2010).

In summary, the implementation of online review sites within the social care sector has to acknowledge and deal with a wide range of challenges. Limitations in the access of users and carers to the internet are a key consideration, along with the low propensity of users to engage in activities such as content generation. Once online, users and their carers will need to be motivated and incentivised to post reviews to ensure that sufficient relevant information is collected to reflect a representative and helpful assessment of the provider. This is in a sector where the turnover of clients is low and protecting the anonymity of potentially vulnerable users is vital. Protecting the identity of care workers also has to be considered carefully. However, the need for anonymity will have an impact on the usefulness of reviews, with information seekers needing an understanding of the reviewer's profile and characteristics in order to assess the quality of information and the relevance for their own needs and preferences. All of these issues exist in what is often a suboptimal decision-making process, with users and carers making choices on providers in stressful and rushed situations. Finally, the notion that reviews can be used in a positive way to improve provider quality may also prove challenging in this market, taking into account the processes which would be needed to access and use this information in practice.

\section{Discussion and Recommendations}

The success of review sites will therefore depend on planning and design which acknowledges and deals with the hurdles outlined in this paper. This section sets out a number of recommendations for how reviews might be effectively harnessed and used effectively in the social care sector in England.

\section{Consolidating Information into a Single Site}

As well as the 35 separate sites on care providers which exist currently in England, other independent sites continue to be launched, some with the option for users to leave feedback (BBC News, 2012; Health Services Journal, 2012). This is in addition to websites set up and run by local authorities. Social care users and their carers not only face the task of tracking down fragmented information and feedback across a range of websites, but they also have the burden of assessing the credibility of the reviewer (and the website) and of interpreting reviewer comments without context. In addition, the quality of information will be affected by the low volume of comments which may appear on any one site. And finally, economies of scale are lost as separate website providers invest in their own design and management processes and resources. Investment is duplicated for functions such as the design of protocols for managing reviews and reviewers, processes and resources for the moderation of comments, processes for managing feedback and communication to providers, and the expertise and skills to design sites which meet accessibility guidelines. 
Investing in a single site would allow the consolidation of information and advice services into one place and allow the site to be promoted as a safe and recommended resource for social care users. Even a single site is unlikely to harness the 'wisdom of crowds', given what we know about the potential for reviews in the social care sector, but there is an opportunity - or responsibility - to consolidate and sort information on behalf of users. There have been many attempts to set up information channels - a scoping review by the University of York identified 47 separate projects in England, with many of these being internet-based 'one-stop shops' (Baxter et al., 2006). Indeed, where social care users are comfortable with using the internet, many would prefer to be directed to a single recommended website (Sykes et al., 2008). This single site could include provider information (including availability), CQC quality information, and feedback from both users (and their carers) and recognised experts.

The investment required to develop a single site would be significant and in addition there is little incentive for a private sector provider to set up this site. Revenue generation opportunities will be limited within a sector which is both financially constrained and has limited supply - the benefits of subscribing to the service or paying for pay-per-click links will not outweigh the costs for providers at the moment. Many of the current sites have been set up by social enterprises and charitable organisations. However given the forecasted growth in the need for social care and the agenda surrounding personalisation, significant investment in effective information channels is needed to support informed consumer choice.

\section{Providing Reliable Provider Information}

One challenge generally not faced by mainstream consumer websites is the need to ensure that all providers are included on provider listings. Not all hotels and restaurants are included on TripAdvisor, although there are clear incentives for it to provide as comprehensive listing as possible. For social care, the most straightforward provider content to include is that drawn directly from the CQC, given that the CQC has a full listing of regulated providers. However, in setting up a website for social care, there are some key decisions to be made regarding inclusion and exclusion criteria. Should the site include providers of both regulated and unregulated services? With the move towards personal budgets, should it include providers of services such as cleaning and gardening? How should lists of personal assistants be managed? How are unsatisfactory providers dealt with are they excluded from the site? Underpinning this is the central question of whether the site should provide comprehensive lists of providers, or recommended providers only. Having established a central strategy for inclusion and exclusion criteria, one option would be for local authorities to be responsible for the management of provider information on the central website. As the body most likely to have intimate knowledge of providers and quality in their local area, they would seem bestsuited to update and maintain reliable information. The local authority is also responsible for gathering current information on user experience, which would be a highly useful addition to a provider's listing.

As well as considering issues regarding the listing of providers, it is important to remember the different circumstances of service users, particularly in terms of funding. It is likely that self-funders will seek information independently as they have more control over their choice of provider. In theory those receiving local authority funding (both directly and through personal budgets) also 
have choice, though it may be restricted. However, these groups may have different requirements for information which need to be considered. Local authorities have a responsibility to support both self-funded and local authority-funded users with information and advice and therefore it seems logical that the management of reliable and up-to-date provider information should be part of its remit.

\section{Assessing Source Credibility}

A site of this type would have to accommodate the difficulties users and their carers have in assessing source credibility, for example, by having identified and labelled experts such as local authorities, lay inspectors, advocacy services or charitable organisations who are familiar with the service. There should be an onus on professionals to generate content, in the likely absence of content from users and carers. While users and carers may have insight into their own care processes, reviews from experts and organisations would be useful to fill in the gaps around technical and clinical aspects of care, as well as whether the provider is delivering quality processes and outcomes for their users overall. An alternative approach would be to publish feedback which has been collected in a structured way from users and carers. This approach has been adopted by the governments in the Netherlands and Sweden - through www.kiesbeter.nl and www.aldreguiden.se respectively. The site should be suitable for professionals too, for example, advocacy and brokerage services, although it should be accompanied by well thought-out processes to ensure that there is clear flagging of providers and 'industry insiders'. In addition, allowing other users to rate the helpfulness of reviews or reviewers may in a small way enable users and carers to indirectly comment on source credibility. This needs to be supported by awareness building activity to ensure that the site has a strong enough profile to attract both reviewers and informationseekers, as well as supplying enough compelling reasons for providers to recognise the value of the feedback and acting upon it.

\section{Designing the Website to Facilitate Rational Decision-making}

The characteristics of social care users and the circumstances around decisions about providers can lead to a sub-optimal decision-making process. In general, strategies for dealing with large amounts of complex information lead people to make more intuitive decisions. Information therefore needs to be presented in a way which somehow deals with the tendency to ignore key pieces of data and to put disproportionate emphasis on information such as user testimonials. Careful design of how information is presented could be used to 'nudge' people towards less stressful decision-making processes and more optimal choices which reflect their needs and preferences. People tend to look at a relatively small amount of information, so it is important that they are presented with the most important data early, with summaries where possible (Boyce et al., 2010). More information is not necessarily better, as studies in health care have found (Peters et al., 2007; Boyce et al., 2010). Instead, information should be tailored to individual needs, both in terms of their needs and preferences for social care, and in individual preferences for how information is presented (Boyce et al., 2010; Fasolo et al., 2010). 


\section{Integrating Internet Information with Other Sources}

Planning the provision of information on social care needs to take into account user preferences. For older people there is a high preference for face-to-face information (Baxter et al., 2008; Sykes et al., 2008; Office of Fair Trading, 2011). Letters are also popular for older people, who like the opportunity to back up written information with face-to-face communication with an informed person (Baxter et al., 2006). Even older people who are experienced with using the internet turn to channels such as face-to-face or phone for easier and less stressful communication (Pfeil et al., 2009). There is also a need for information to be available in different formats, for example, large type, easy-to-read styles and video formats, as well as verbal information for people who are visually impaired or who have low levels of literacy (Baxter et al., 2008), or specifically for people with learning difficulties (Joseph Rowntree Foundation, 2004). Other groups for whom specific information is needed include Black and Minority Ethnics and those with chaotic lifestyles (Baxter et al., 2006). Therefore, even for social care users and their carers who are connected and confident with using the internet, there is a need for information from other channels. This should also be supported by investment in advocacy and brokerage schemes to improve the overall information seeking process (Equalities and Human Rights Commission, 2011).

The best chances of establishing a successful and useful source of web-based information will be to integrate it effectively with other channels. This should be a two-way process. The site should include signposting out to other resources and channels, and to official sources of information. The address and content of the site should also be promoted by other information sources. However, promotion by other sources will be dependent on the quality and usefulness of the site - investing in the site itself will be a key driver for the extent to which it is used and promoted by other stakeholders

\section{Using Functionality and Design to Offer Enhanced Services}

As this paper has shown, a major obstacle for social care reviews is the need to preserve the anonymity of users and care professionals. However, social media and networking technology provides opportunities to allow people to communicate in a number of different ways. TripAdvisor offers a number of different modes of communication, for example, peer-to-peer communication through private messaging, and these types of application should be explored for social care. A relative or carer may be reticent about posting a review online, but they might be happy to be flagged as someone for information seekers to contact privately through the site. The opportunity to open up one-on-one first was identified as one way of subsequently engaging older people in online groups (Pfeil et al., 2009). This type of service could be useful for employers of personal assistants to exchange references without sharing personal details such as addresses or contact information although this would be contingent upon the establishment of a voluntary register to facilitate the identification of personal assistants. The many different types of social care will merit slightly different approaches, with the need for private contact with other users and carers varying depending on the nature of the service and the requirement for anonymity. This type of approach opens up a whole raft of design and implementation challenges. In particular, it will be important to consider how identities might be validated and protected, for example, to ensure that reviewers are genuine and not professionals posting reviews, either positive or negative, on behalf of providers. 
However, the benefits of this type of service might be greater than the strategy of publishing user feedback.

\section{Establishing Processes for Service Improvement}

The importance of exposing poor provider behaviour is clear. Cases such as the events at Winterbourne View (Care Quality Commission, 2011) highlight the need for better communication processes. In addition, a report by the Equalities and Human Rights Commission highlighted that the lack of regulation in this area creates a high need for protecting people from 'abuse, harm and neglect' (Equalities and Human Rights Commission, 2011, p64). Hennig-Thurau and colleagues (2004) identified that, in addition to the motivators described by Sundaram and colleagues (1998), some consumers might use the internet as an easier route for complaints, particularly if complaining directly to the provider has not been productive. It would therefore be appropriate to consider how this website might serve as a supplementary channel to capture complaints and feedback. However the limitations of this channel in supporting quality improvement should not be under-estimated, and it should not be considered as a core tool for whistleblowing or safeguarding processes. Even for relatively innocuous feedback, careful thought and planning would be needed to design processes which support the routing of feedback to providers effectively.

\section{Conclusion}

Notwithstanding the challenges outlined in this paper, review sites will have a useful place in social care if they are designed carefully to acknowledge the specific characteristics of the sector and users of social care and their carers. Many service users and their carers are connected to the internet, and it is to be expected that future generations of older people will be more familiar and confident with using technology, setting aside age-related difficulties. The opportunity is to design information portals for these users which attempt to overcome the challenges described here, while providing a service which could enhance the experience many of those seeking social care. Strategic planning and design is needed to collect sufficient amounts of meaningful quality information from users, carers and other representatives and to present it in ways which can be utilised effectively by both information seekers and providers. 


\section{References}

Adams, L. and Godwin, L. (2008) 'Employment aspects and workforce implications of direct payments. Prepared for Skills for Care', London, IFF Research Ltd.

Advertising Standards Authority (2012) 'ASA Adjudication on TripAdvisor LLC', http://www.asa.org.uk/ASA-action/Adjudications/2012/2/TripAdvisor-LLC/SHP ADJ 166867.aspx [Accessed 1 February 2012]

Amazon (2012a) 'General Review Creation Guidelines'. http://www.amazon.co.uk/gp/communityhelp/customer-reviews-guidelines?ie=UTF8\&pageDisplay=popUp [Access 26 March 2012]

Amazon (2012b) 'How ranking works'. http://www.amazon.co.uk/gp/customerreviews/guidelines/top-reviewers.html [Accessed 17 March 2012]

Baxter, K., Glendinning, C. and Clarke, S. (2006) 'Scoping Review on Access to Information about Social Care Services', York, Social Policy Research Unit, University of York.

Baxter, K., Glendinning, C. and Clarke, S. (2008) 'Making informed choices in social care: the importance of accessible information', Health \& Social Care in the Community, 16(2), pp. 197-207.

BBC News (2011) 'Plans for greater scrutiny of elderly care in England'.

http://www.bbc.co.uk/news/health-16125463 [Accessed 24 March 2012]

BBC News (2012) 'Good Care Guide launch prompts concerns'. http://www.bbc.co.uk/news/uk17084680 [Accessed 18 February 2012]

Berwick, D.M., James, B. and Coye, M.J. (2003) 'Connections between quality measurement and improvement', Med Care, 41(1 Suppl), pp. I30-38.

Blank, G. and Reisdorf, B.C. (2012) 'The Participatory Web', Information, Communication \& Society, pp. 1-18.

Boyce, T., Dixon, A., Fasolo, B. and Reutskaja, E. (2010) 'Choosing a high-quality hospital: the role of nudges, scorecard design and information', The King's Fund.

Brown, J., Broderick, A. and Lee, N. (2007) 'Word of mouth communication within online communities: Conceptualizing the online social network', Journal of Interactive Marketing, 21(3), pp. $2-20$.

Burgess, G. (2010) 'Evaluation of the FirstStop information and advice service for older people, their families and their carers', Cambridge, Cambridge Centre for Housing and Planning Research.

Care Quality Commission (2011) 'CQC report on Winterbourne View confirms its owners failed to protect people from abuse'. http://www.cqc.org.uk/media/cqc-report-winterbourne-view-confirmsits-owners-failed-protect-people-abuse [Accessed 24 March 2012] 
Care Quality Commission (2012) 'Tell us about your care' pilot projects begin'.

http://www.cqc.org.uk/public/news/\%E2\%80\%98tell-us-about-your-care\%E2\%80\%99-pilot-projectsbegin [Accessed 17 March 2012]

carehomes.co.uk (2012) 'Latest Google Analytics Stats for carehome.co.uk'. http://www.carehome.co.uk/advertise.cfm/page/carehomeoverview [Accessed 24 March 2012]

Chang, J.T., Hays, R.D., Shekelle, P.G., MacLean, C.H., Solomon, D.H., Reuben, D.B., Roth, C.P., Kamberg, C.J., Adams, J., Young, R.T. and Wenger, N.S. (2006) 'Patients' global ratings of their health care are not associated with the technical quality of their care', Ann Intern Med, 144(9), pp. 665-672.

Commission for Social Care Inspection (2009) 'CSCI Quality Ratings: Market Research Report'.

David, S. and Pinch, T. (2005) 'Six degrees of reputation: The use and abuse of online review and recommendation systems'.

http://frodo.lib.uic.edu/ojsjournals/index.php/fm/article/view/1315/1235 [Accessed 26 March 2012]

Davie, E. (2011) 'GPC calls for practice rating on NHS Choices to be axed as GPs query one in 10 comments ', Pulse Today, 11 July 2011.

Davies, B. and Knapp, M. (1980) Old people's homes and the production of welfare, London, Routledge.

Davies, S. and Nolan, M. (2003) "Making the best of things': relatives' experiences of decisions about care-home entry', Ageing and Society, 23, pp. 429-450.

Dellarocas, C. (2006) 'Strategic manipulation of Internet opinion forums: Implications for consumers and firms', Management Science, 52(10), pp. 1577-1593.

Department of Health (2012) Caring for our future: reforming care and support. Presented to Parliament by the Secretary of State for Health by Command of Her Majesty. Cm8378. London.

Department for Work and Pensions (2012) 'Disability facts and figures'.

http://odi.dwp.gov.uk/disability-statistics-and-research/disability-facts-and-figures.php\#ls [Accessed 3 March 2012]

Disability Rights Commission (2004) 'The Web. Access and Inclusion for Disabled People', London.

Dixon, A., Robertson, R., Appleby, J., Burge, P., Devlin, N. and Magee, H. (2010) 'Patient Choice. How Patients Choose and How Providers Respond', London, King's Fund.

Duan, W.J., Gu, G. and Whinston, A.B. (2008) 'Do online reviews matter? - An empirical investigation of panel data', Decision Support Systems, 45(4), pp. 1007-1016.

Dutton, W. and Blank, G. (2011) 'Oxford Internet Survey 2011. Next Generation Users: the Internet in Britain', Oxford, Oxford Internet Institute. 
Eborall, C., Fenton, W. and Woodrow, S. (2010) 'The State of the Adult Social Care Workforce in England, 2010', Leeds, Skills for Care.

Equalities and Human Rights Commission (2011) 'Close to home. An inquiry into older people and human rights in home care', http://www.equalityhumanrights.com/legal-and-policy/inquiries-andassessments/inquiry-into-home-care-of-older-people/, Equalities and Human Rights Commission.

Fagerlin, A., Wang, C. and Ubel, P.A. (2005) 'Reducing the influence of anecdotal reasoning on people's health care decisions: Is a picture worth a thousand statistics?', Medical Decision Making, 25(4), pp. 398-405.

Fasolo, B., Reutskaja, E., Dixon, A. and Boyce, T. (2010) 'Helping patients choose: how to improve the design of comparative scorecards of hospital quality', Patient Education and Counseling, 78(3), pp. 344-349.

Finucane, M.L., Slovic, P., Hibbard, J.H., Peters, E., Mertz, C.K. and MacGregor, D.G. (2002) 'Aging and decision-making competence: An analysis of comprehension and consistency skills in older versus younger adults considering health-plan options', Journal of Behavioral Decision Making, 15(2), pp. 141-164.

Foley, P.D., Alfonso, X., Fisher, J. and Bradbrook, G. (2005) 'eGovernment: Reaching socially excluded groups?'. http://www.idea.gov.uk/idk/core/page.do?pageld=1074872 [Accessed 8 March 2012]

Forder, J. and Fernandez, J.L. (2011) 'Length of stay in care homes. A report commissioned by BUPA.', London, Personal Social Services Research Unit.

Forman, C., Ghose, A. and Wiesenfeld, B. (2008) 'Examining the relationship between reviews and sales: The role of reviewer identity disclosure in electronic markets', Information Systems Research.

Fung, C.H., Lim, Y.W., Mattke, S., Damberg, C. and Shekelle, P.G. (2008) 'Systematic review: the evidence that publishing patient care performance data improves quality of care', Ann Intern Med, 148(2), pp. 111-123.

Grabowski, D.C. and Town, R.J. (2011) 'Does Information Matter? Competition, Quality, and the Impact of Nursing Home Report Cards', Health Services Research, 46(6), pp. 1698-1719.

Gretzel, U., Yoo, K.H. and Purifoy, M. (2007) 'Online travel review study: Role and impact of online travel reviews', Texas A \& M University. Department of Recreation, Park and Tourism Sciences. Laboratory for Intelligent Systems in Tourism.

Hargittai, E. and Walejko, G. (2008) 'The Participation Divide: Content creation and sharing in the digital age', Information, Communication \& Society, 11(2), pp. 239-256.

Harlock, J. (2009) 'Personalisation: Rhetoric to reality', London, National Council for Voluntary Organisations.

Hatton, C. and Waters, J. (2011) 'The National Personal Budget Survey', In Control, Lancaster University. 
Health Services Journal (2012) "TripAdvisor' comes to care homes', HSJ, 9 February 2012.

Helsper, E. (2008) 'Digital Inclusion: An Analysis of Social Disadvantage and the Information Society', Department for Communities and Local Government.

Hennig-Thurau, T., Gwinner, K., Walsh, G. and Gremler, D. (2004) 'Electronic word-of-mouth via consumer-opinion platforms: what motivates consumers to articulate themselves on the internet?', Journal of Interactive Marketing, 18(1).

Hibbard, J.H., Slovic, P., Peters, E. and Finucane, M.L. (2002) 'Strategies for reporting health plan performance information to consumers: evidence from controlled studies', Health Services Research, 37(2), pp. 291-313.

homecare.co.uk (2012) 'Latest Google Analytics Stats for homecare.co.uk'. http://www.homecare.co.uk/advertise.cfm/page/carehomeoverview [Accessed 24 March 2012] Hulse, T. (2010) 'Steve Kaufer, co-founder of TripAdvisor', BA Business Life, 13 August 2010. Joseph Rowntree Foundation (2004) 'The importance and availability of peer support for people with learning difficulties accessing direct payments', York, Joseph Rowntree Foundation.

Keates, N. (2007) 'Deconstructing TripAdvisor', Wall Street Journal, 1 June 2007.

Klein, L.R. (1998) 'Evaluating the potential of interactive media through new lens: Search versus experience goods', Journal of Business Research, 41(3), pp. 195-203.

Knapp, M., Prince, M., Albanese, E., Banerjee, S., Dhanasiri, S. and Fernandez, J. (2007) 'Dementia UK: The Full Report', London, Alzheimer's Society.

Lagu, T., Hannon, N.S., Rothberg, M.B. and Lindenauer, P.K. (2010) 'Patients' evaluations of health care providers in the era of social networking: an analysis of physician-rating websites', J Gen Intern Med, 25(9), pp. 942-946.

Lagu, T. and Lindenauer, P.K. (2010) 'Putting the public back in public reporting of health care quality', JAMA, 304(15), pp. 1711-1712.

Laverty, A.A., Smith, P.C., Pape, U.J., Mears, A., Wachter, R.M. and Millett, C. (2012) 'High-Profile Investigations Into Hospital Safety Problems In England Did Not Prompt Patients To Switch Providers', Health Affairs, 31(3), pp. 593-601.

Law Commission (2011) 'Adult Social Care. HC941', London, The Stationery Office.

Linden, G., Smith, B. and York, J. (2003) 'Amazon.com recommendation - Item-to-item collaborative filtering', leee Internet Computing, 7(1), pp. 76-80.

Lopez, A., Detz, A., Ratanawongsa, N. and Sarkar, U. (2012) 'What Patients Say About Their Doctors Online: A Qualitative Content Analysis', J Gen Intern Med.

Mannion, R., Davies, H. and Marshall, M. (2005) 'Impact of star performance ratings in English acute hospital trusts', J Health Serv Res Policy, 10(1), pp. 18-24. 
Mata, R., Schooler, L.J. and Rieskamp, J. (2007) 'The aging decision maker: cognitive aging and the adaptive selection of decision strategies', Psychol Aging, 22(4), pp. 796-810.

McCartney, M. (2009) 'Will doctor rating sites improve the quality of care? No', British Medical Journal, 338, p. b1033.

Mukamel, D.B., Spector, W.D., Zinn, J.S., Huang, L., Weimer, D.L. and Dozier, A. (2007) 'Nursing homes' response to the nursing home compare report card', J Gerontol B Psychol Sci Soc Sci, 62(4), pp. S218-225.

Munro, J. \& Ebbutt, K. 2011. Beware of the pitfalls of rating care homes. Available from: http://www.guardian.co.uk/society/2011/dec/15/care-homes-review-website-pitfalls [Accessed 15 December 2011].

National Audit Office (2011) 'Oversight of user choice and provider competition in care markets. Report by the Comptroller and Auditor General HC 1458 Session 2010-2012', London.

Nelson, P. (1970) 'Information and Consumer Behavior', Journal of Political Economy, 78(2), pp. 311329.

Nelson, P. (1974) 'Advertising as Information', Journal of Political Economy, 82(4), pp. 729-754.

Netten, A., Darton, R., Curtis, L. and Britain, G. (2001) 'Self-funded Admissions to Care Homes. Research Report No. 159', Leeds, Department of Work and Pensions.

Neville, S. (2011) 'Lansley unveils rate-your-NHS indicators', Financial Times, 7 December 2011. NHS Choices (2011) 'Improving health, improving lives. NHS Choices Annual Report 2011', London, NHS.

NHS Choices (2012) 'NHS Choices terms and conditions'.

http://www.nhs.uk/aboutNHSChoices/aboutnhschoices/termsandconditions/Pages/commentspolic y.aspx [Accessed 20 February 2012]

NHS Information Centre for Health and Social Care (2012a) 'Personal Social Services: Expenditure and Unit Costs -England 2010-11- Final Release', Leeds.

NHS Information Centre for Health and Social Care (2012b) 'Social Care and Mental Health Indicators from the National Indicator Set - 2010-11 - Final Release', Leeds, NHS Information Centre for Health and Social Care,.

O'Connor, P. (2010) 'Managing a hotel's image on TripAdvisor', Journal of Hospitality Marketing \& Management, 19(7), pp. 754-772.

Office for National Statistics (2010) 'Internet Access 2010 Households and Individuals. Statistical Bulletin', Office for National Statistics. 
Office for Public Management, Essex Coalition for Disabled People and Essex County Council (2010) 'Delivering personal budgets for adult social care: Reflections from Essex', London, Office for Public Management.

Office of Fair Trading (2011) 'Evaluating the impact of the 2005 OFT study into care homes for older people. Prepared for the Office of Fair Trading by GHK', Office of Fair Trading.

Parasuraman, A., Zeithaml, V.A. and Berry, L.L. (1985) 'A conceptual model of service quality and its implications for future research', The Journal of Marketing, 49(4), pp. 41-50.

Park, D., Lee, J. and Han, I. (2007) 'The effect of on-line consumer reviews on consumer purchasing intention: The moderating role of involvement', International Journal of Electronic Commerce, 11(4), pp. 125-148.

Payne, J.W., Bettman, J.R. and Johnson, E.J. (1993) The Adaptive Decision Maker, Cambridge, Cambridge University Press.

Peters, E., Dieckmann, N., Dixon, A., Hibbard, J.H. and Mertz, C.K. (2007) 'Less is more in presenting quality information to consumers', Med Care Res Rev, 64(2), pp. 169-190.

Pfeil, U., Zaphiris, P. and Wilson, S. (2009) 'Older adults' perceptions and experiences of online social support', Interacting with Computers, 21(3), pp. 159-172.

Pinch, T. and Kesler, F. (2011) 'How Aunt Ammy Gets Her Free Lunch: A Study of the Top-Thousand Customer Reviewers at Amazon.com.'. http://www.freelunch.me/filecabinet [Accessed 26 March 2012]

Raphael, A. (2011) 'Selling the indefensible', Good Hotel Guide, London, Good Hotel Guide.

Redish, J. and Chisnell, D. (2004) 'Designing web sites for older adults: A review of recent literature', Prepared for American Association of Retired People.

Royal College of Nursing (2012) 'Persistent challenges to providing quality care. An RCN report on the views and experiences of frontline nursing staff in care homes in England', London, Royal College of Nursing.

Scourfield, P. (2005) 'Implementing the community care (Direct payments) act: Will the supply of personal assistants meet the demand and at what price?', Journal of Social Policy, 34, pp. 469-488.

Slovic, P. (1995) 'The Construction of Preference', American Psychologist, 50(5), pp. 364-371.

Social Care Institute for Excellence (2012) 'Find Me Good Care'.

http://www.findmegoodcare.co.uk/?dm i=4O5,PLRA,4ZFGTG,22J56,1 [Accessed 28 February 2012]

Spool, J.M. (2009) 'The Magic Behind Amazon's 2.7 Billion Dollar Question', User Interface Engineering, User Interface Engineering. http://www.uie.com/articles/magicbehindamazon/\%5C [Accessed 17 March 2012]

Steen, I. (2012) 'Personal communication', 14 March 2012. 
Stevenson, D.G. (2006) 'Is a public reporting approach appropriate for nursing home care?', J Health Polit Policy Law, 31(4), pp. 773-810.

Streitfield, D. (2011) 'In a Race to Out-Rave, 5-Star Web Reviews Go for \$5', New York Times, 19 August 2011.

Sundaram, D., Mitra, K. and Webster, C. (1998) 'Word-of-mouth communications: A motivational analysis', Advances in Consumer Research, 25(1), pp. 527-531.

Surowiecki, J. (2004) The wisdom of crowds : why the many are smarter than the few and how collective wisdom shapes business, economies, societies, and nations, London, Little, Brown.

Sykes, W., Hedges, A., Groom, C. and Coleman, N. (2008) 'Opportunity Age information indicators feasibility study. A report of research carried out by Independent Social Research on behalf of the Department for Work and Pensions, London', London, Department for Work and Pensions.

Todd, R. (2012) 'Patient Opinion to cover social care', e-Health Insider. http://www.ehi.co.uk/news/EHI/7610/patient-opinion-to-cover-social-care [Accessed 15 March 2012]

TripAdvisor (2012a) 'Help Center'. http://www.tripadvisor.co.uk/help [Accessed 11 March 2012] TripAdvisor (2012b) 'TripAdvisor website'. http://www.tripadvisor.co.uk/pages/about_us.html [Accessed 8 March 2012]

Ubel, P.A., Jepson, C. and Baron, J. (2001) 'The inclusion of patient testimonials in decision aids: effects on treatment choices', Medical Decision Making, 21(1), pp. 60-68.

Weathers, D., Sharma, S. and Wood, S.L. (2007) 'Effects of online communication practices on consumer perceptions of performance uncertainty for search and experience goods', Journal of Retailing, 83(4), pp. 393-401.

Zhu, F. and Zhang, X.Q. (2010) 'Impact of Online Consumer Reviews on Sales: The Moderating Role of Product and Consumer Characteristics', Journal of Marketing, 74(2), pp. 133-148.

Zhuo, J. (2010) 'Where anonymity breeds contempt', New York Times, 29 November 2010. 